\title{
DEVELOPMENT FEATURES OF EMOTIONAL INTELLEGENCE \\ IN THE CONDITIONS OF INFORMAL EDUCATION \\ (CROSS CULTURAL ASPECT)
}

https://doi.org/10.37096/SHDISJ-20-1.1-0001

\author{
Daria Kolodych \\ ORCID: 0000-0002-5960-9553 \\ Jolanta Ewa Zarzycka-Dertli \\ ORCID: 0000-0003-4651-8561
}

\begin{abstract}
The research involved 138 Ukrainian and 122 Vietnamese teenagers. The distribution of boys and girls was fairly uniform: there were 78 boys and 80 girls among, 63 boys and 59 girls among Vietnamese. The age of the respondents ranged from 11 to 15 years, the average age of the Ukrainian sample was 13.8, and the Vietnamese sample was 12.10. All children attended English language courses in small groups, were studied willingly and voluntarily. We used N. Hall`s EQ questionnaire to measure intra personal intelligence, interpersonal intelligence, understanding emotions, managing emotions and general level of emotional intelligence, which consists in all the mentioned elements. In addition, we examined the level of subjective control (J. Rotter's Locus of Control Scale test), lifestyle (The Life Style Index by R. Plutchik, H. Kellerman, and H. Conte (LSI)), professional inclinations (J. Holland`s test), self-esteem in interpersonal relationships (Pip Wilson`s Blob Tree test). Revealed that emotional intelligence in teenagers affects their position in the team, professional inclinations, to some extent - the locus of control and defense mechanisms. There is a difference between Ukrainian and Vietnamese teenagers on interpersonal emotional intelligence and emotion recognition. Therefore, methods of teaching foreign language in Vietnam should include elements of acting, pay more attention to the definition of emotions. The ability to apply educational technologies aimed not only at learning, but also at the development of emotional intelligence, depending on the ethnic and cultural characteristics of children, should be included in the training program for foreign language teachers.
\end{abstract}

Keywords. Emotional intelligence, defense mechanisms, education, cross-cultural research.

\section{Introduction}

Nowadays there is an active development of informal education: courses, trainings, clubs and sections are becoming a common option for obtaining the knowledge necessary for further life and professional development. One of the distinctive options for information education has been foreign language courses that offer English to teens. The main focus (unlike school course in foreign language) focuses on the development of communication - the ability to freely express their thoughts, fluently speak and understand others. During this process, we believe, is the development of emotional intelligence, which was the subject of our study.

Previous studies analysis. In the context of globalization, the role of foreign 
"SOCIALIZATION \& HUMAN DEVELOPMENT" INTERNATIONAL JOURNAL

languages increases, because they actively acquire the status of a political, socioeconomic and cultural mechanism of international understanding in the world's community. This is due to several reasons, including:

- In the last decade, began to actively develop Ukrainian international relations with the European Union in various fields, such as business, education, social projects, lots of foreign companies, enterprises and organizations started to cooperate with Ukraine;

- The modern world has become more multinational and multilingual: on the one hand, the process of globalization and economic competition is intensifying, and on the other, the role of the national mentality is increasing;

- There have been changes in the labor market: almost everywhere requires professionals who have it-literacy and know at least one foreign language;

- society has become more mobile, enabling Ukrainian citizens to travel, study and work abroad [5].

The European pedagogical literature distinguishes three components of the educational system and it is generally accepted to use the following terms: formal education; - non-formal education; informal education [6]. For the first time, formal, non-formal and informal education was defined at the legislative level in Ukraine. Article 8 (Types of Education) of the recently adopted Law of Ukraine on Education provides:

1. A person uses his or her right to lifelong education through formal, nonformal and informal education. The state approves these types of education, creates conditions for the development of educational activities subjects that provide appropriate educational services and encourage education of all kinds.

2. Formal education is the education that is acquired according to educational programs in correspondence with certain levels of education legislation, disciplines specialties (professions) and provides specified standard educational results for learners relevant to their level of education and qualifications approved by the state.

3. Non-formal education - the education that is acquired usually by educational programs and does not include the awarding of state-approved educational qualifications by level of education, but could finish assigning professional and / or educational awarding partial qualifications.

4. Informal education (self-education) is an education that involves the selforganized acquisition by a person of certain competencies, in particular in the course of daily activities related to professional, social or other activities, family or leisure.

5. Learning outcomes gained through non-formal and / or informal education recognized in formal education system in accordance with the law. [5]

L. Moskalenko [3], as a result of a study of Ukrainians' involvement in information education, believes that the results of the study "Trends in the development of non-formal education in Ukraine" make a major conclusion - nonformal education has become a significant component of education in the country. It is advisable to further promote non-formal education and improve its effectiveness: to promote the concept of lifelong learning and non-formal education among different age, professional groups, with different levels of education; create conditions for establishing cross-sectoral partnerships in the field of non-formal education; create conditions for the spread of areas related to 
informal education as a source of new jobs. O. Vlasova [2] considers the emotional intelligence development specifics of students, but only in Ukraine, and J. Breus [1] - the role of emotional intelligence in pedagogical education. S. Yablokov [7] draws attention to the importance of informal education in the foreign language learning process.

However, the problem remains unattended is informal teacher training education, including those who teach or plan to teach students from other cultures. Training future teachers in the theory and methods of teaching foreign languages should be carried out in general theoretical and methodological aspects. Postgraduate Education, which provides terminal foreign languages teachers training at the Institute of Postgraduate Education, should be based on the andragogical principles use. The foreign language teachers self-education importance should be emphasized. Their periodic training in the postgraduate pedagogical education system does not provide timely qualitative updating of professional knowledge, as the globalization process and educational technologies changes are rapidly developing. Therefore, one of the most important tasks of teachers' continuous education is self-developing skills that allow them to update theoretical knowledge and practical training to improve foreign language courses and its teaching methods independently. In addition, the vocational training of foreign language teachers should be proactive. Prepared in this way the teacher will be able to navigate changes in the concepts and content of the course, the new textbooks conclusion, teaching aids, preparing game- and training-style classes etc. Non-formal and informal education, which is not necessarily organized and systematic, can take place outside the traditional school and university education system and covers people of all ages. In this sector innovative approaches are most often applied, innovative teaching methods are tried. Foreign language teachers who have special access to modern information technologies and are interested in their widespread use, can actively use the opportunities of non-formal and informal education systems. In Ukraine, the existence of non-formal education covers the following areas: extracurricular education; postgraduate and adult education; civic education (diverse activities of NGOs); school and student self-government (due to the possibility of acquiring managerial, organizational, communication and other skills); educational initiatives to develop additional skills and abilities (computer and language courses, hobby groups, etc.). Recently Ukraine started to operate international language education projects.

Non-formal education can take place in any environment (school, family, church, community, etc.); at any age (from birth to death), which once again confirms the existence of non-formal education as part of lifelong learning; in individual or group form. Non-formal education can both complement and reinforce formal education, and contradict it, while remaining an important element that needs the necessary attention, study, implementation and use in the modern world to ensure a decent educational level for Ukrainian citizens. Thus, of particular relevance in our time become problems associated with the reform and development of the national system of continuous education of teachers, including foreign languages. It should be aimed at solving problems of professional and 
"SOCIALIZATION \& HUMAN DEVELOPMENT" INTERNATIONAL JOURNAL

personal development of teachers, specific activities and their range of functional responsibilities that are constantly changing.

However, the availability of informal education contributes not only to the knowledge acquisition as such, but also to the development of students and teachers' communicative competence and emotional intelligence. D. Goleman said: "What would have become of our school (and children), if the education program included the development of emotional intelligence capable of causing other people live feedback? Moreover, any employer would be happy to welcome such people into the ranks of their employees, those who have good competency in these life-important skills. This would also benefit the people themselves, which would result in partial elimination of social ailments - such as acts of violence, alcohol or drug abuse - that result from a lack of balance and self-control. The whole society would benefit from that - higher level of tolerance, care and personal responsibility would be a great boon for it"[3, p. 11].

J. Breus [1] suggested priority areas of emotional intelligence development during professional training in higher education institutions:

- understanding your own emotions and the emotions of others and as a result, the capacity for professional reflection, self-awareness as a person, as a professional, awareness of self-actions, behavior;

- self-control and self-regulation of emotions and as a result, the availability of personal professional identity, professional meanings (personal professional knowledge, professional attitude to the subject of work, professional ideals, norms and values, meaningful motives of professional activity);

- Awareness of their own emotions and management and, as a result, maintaining the health of the individual (physical, professional, psychological);

- The use of emotions, particularly in conflict situations and as a result, the ability to resolve conflicts in the professional activities and to sustain relationships with others (co-workers, supervisors, subordinates).

Some studies have shown that EI positively associated with quality of life, based on indicators of life satisfaction. The relation between EI, branching human social environment and social aspects of life satisfaction was found. A study of college students showed that a high level of EI indicators correlate with empathy and fewer conflicts, more interaction with peers. This suggests that EI is related to the social interaction quality. Similarly, a study of high-EI teenagers demonstrates their ability to manage other people's emotions successfully, potentially protecting them from negative emotions related to interpersonal communication.

Thus, we believe that the development of communication skills and emotional intelligence in the system of information education will promote a higher level of personal perception of their own well-being, as well as facilitate teenagers' transition to independent living and inclusion in new economically driven relationships in society. However, it should be noted that the researchers do not pay attention to ethnocultural features of the teenagers emotional intelligence development, which is the subject of research in this article.

Therefore, the purpose of our empirical study was to compare the 
"SOCIALIZATION \& HUMAN DEVELOPMENT" INTERNATIONAL JOURNAL

emotional intelligence features of teenagers who are involved in the informal education system in Ukraine and Vietnam.

\section{Research methods}

The research involved 138 Ukrainian and 122 Vietnamese teenagers. The distribution of boys and girls was fairly uniform: there were 78 boys and 80 girls among, 63 boys and 59 girls among Vietnamese. The age of the respondents ranged from 11 to 15 years, the average age of the Ukrainian sample was 13.8, and the Vietnamese sample was 12.10. All children attended English language courses in small groups, were studied willingly and voluntarily. We used N. Hall`s EQ questionnaire to measure intra personal intelligence, interpersonal intelligence, understanding emotions, managing emotions and general level of emotional intelligence, which consists in all the mentioned elements. In addition, we examined the level of subjective control (J. Rotter's Locus of Control Scale test), lifestyle (The Life Style Index by R. Plutchik, H. Kellerman, and H. Conte (LSI)), professional inclinations (J. Holland's test), self-esteem in interpersonal relationships (Pip Wilson`s Blob Tree test). This made it possible to identify links system between emotional intelligence level and its components with other mental symptoms, such as subjective control level, psychological defense mechanisms, types of professional inclination and the child`s position in a group.

\section{Research results}

As a data obtained processing result, internal connections were found within the emotional intelligence test itself.

The interpersonal emotional intelligence indicator has the following correlative relations: average positive correlation with the scale Intra-personal emotional intelligence $\left(0.436^{* *}, \mathrm{p}=0.001\right)$; a strong positive correlation with Understanding Emotions (0.797 **, p = 0.000 ); average positive correlation with the Emotions Management scale $(0.578 * *$, $\mathrm{p}=0.001)$; a strong positive correlation with the Total Level of Emotional Intelligence $(0.831 * *, p=0.000)$. The links with psychological defenses were interesting: this parameter was not related to most types of defense mechanisms, only the average negative correlation with Compensation was found $\left(-0.375^{* *}, \mathrm{p}=\right.$ 0.004). This means that the high level of interpersonal emotional intelligence person experiences less stress and does not use this type of psychological protection as compensation. It was also found links with professional inclinations: weak negative correlation with Realistic type $(*-0.262, p$ $=0.049$ ); weak negative correlation with Convention type $(-0.330 *, \mathrm{p}=0.012)$; weak positive correlation with Artistic type $(0.276 *, p=0.038)$. Intra personal emotional intelligence indicator has the following correlation: a strong positive correlation with the Emotion Understanding Scale $(0.620 * *, p=0.000)$; strong positive correlation with the Emotion Management scale $(0.878 * *, \mathrm{p}=$ 0.000 ); a strong positive correlation with the Total Emotional Intelligence $(0.863 * *$, $\mathrm{p}=0.000)$ scale. It was found a number of internal connections between emotional intelligence and personal self-esteem in interpersonal relationships: a weak negative correlation with Directivity ($0.267 *, \mathrm{p}=0.045)$; average negative correlation with Hostility $(-0.362 * *, \mathrm{p}=$ 0.006 ); a weak negative correlation with Inconsistency $\left(-0.296^{*}, \mathrm{p}=0.025\right)$. We could say that intra personal emotional intelligence makes teenagers less hostile 
"SOCIALIZATION \& HUMAN DEVELOPMENT" INTERNATIONAL JOURNAL

and more accommodating in interpersonal relationships. At the same time, unlike the previous variable, the intra personal emotional intelligence has a weak positive correlation with such psychological defenses as Denial $(0.272 *, \mathrm{p}=0.041)$; Intellectualization $(0.302 *, \mathrm{p}=0.023)$; average negative correlation with Regression $\left(-0.511^{* *}, \mathrm{p}=0.000\right)$. This means that with the level of the first, second level decreases, and vice versa; weak negative correlation with the overall strength of defenses $\left(^{*}-0.270, \mathrm{p}=0.042\right)$. This means that intra personal intelligence has no clear impact on the stress level and psychological defenses. In addition, this type of emotional intelligence has no significant effect on teenagers` professional inclinations. Emotion Understanding is related to: weak negative correlation with Inconsistency $(-0.336 *$, p $=0.011)$; weak negative correlation with Regression (-0.269*, p = 0.043); weak negative correlation with Compensation ($0.281 *, \mathrm{p}=0.034)$. This means that such indicator as understanding emotions reduces the overall tension of interpersonal relationships, reduces symptoms of psychological defenses. This is confirmed by a weak positive correlation of the parameter defined with the Interpersonal Relationship Internality $(0.282 *, \mathrm{p}=$ $0.033)$. This parameter is also associated with teenagers ' professional inclinations: it has an average negative correlation with the Convention type $(-0.349 * *, \mathrm{p}=0.008)$; weak positive correlation with Artistic type $\left(0.334^{*}, \mathrm{p}=0.011\right)$.

While in the sample of Vietnamese students, the indicator "Understanding of emotions" is associated with a weak negative correlation with the psychological protection of "Suppression" $(-0.293 *, \mathrm{p}=$ 0.028); and the parameter "Emotion
Management" is associated with a weak positive correlation with the "Internality of interpersonal relationships" $\left(0.338^{*}, \mathrm{p}=\right.$ 0.012 ). This means that together indicators such as understanding and managing emotions reduce the overall tension of interpersonal relationships and reduce the manifestations of suppression as a psychological defense.

Thus, we can predict that the emotional intelligence development will have a positive effect on teenagers' interpersonal relationships, reducing levels of conflict and force interaction. Emotional intelligence is particularly important for teenagers who are focused on the creative profession - the artistic type, and is not very necessary for those who are focused on conventional and economic specialties. The connection between emotional intelligence and psychological defenses is not one-way, and needs further study. In any case, we can consider that teenagers would benefit from the emotional intelligence development in such kind of informal education activity as English language courses. Another issue that arose in our study was the presence or absence of differences in the emotional intelligence development between Ukrainian and Vietnamese students. We tested the statistical difference between the sample scores by the average of the emotional intelligence of Ukrainian and Vietnamese children. For this purpose, we used the comparing averages $\mathrm{T}$-Student criterion according to the emotional intelligence questionnaire test.

Statistically significant differences were found in the following indicators:

Interpersonal emotional intelligence $($ Sig. $(2$-tailed $)=0.000)$,

Intrapersonal emotional

intelligence $($ Sig. $(2$-tailed $)=0.026)$, 
"SOCIALIZATION \& HUMAN DEVELOPMENT" INTERNATIONAL JOURNAL

- Emotions understanding (Sig. (2tailed) $=0.000$ ),

- Emotion management (Sig. (2tailed) $=0.005$,

- Total Emotional Intelligence level (Sig. $(2$-tailed $)=0.000)$.

Distribution of average scores for each scale shown in Table 1.

As shown in Table 1, the differences relate not all components of emotional intelligence: Intrapersonal emotional intelligence and emotion management had no significant differences, while the cultural features of Vietnamese culture led to a lower level of interpersonal intelligence and Emotions understanding. This can be explained by the fact that emotional restraint, the ability to regulate, and not openly demonstrate their own emotions were considered the norm of this culture.

Tab. 1. Average scores of teenagers`emotional intelligence.

\begin{tabular}{|l|l|l|l|}
\hline \multicolumn{1}{|c|}{ Indicators } & \multicolumn{1}{|c|}{ Ukraine } & \multicolumn{1}{|c|}{ Vietnam } & \multicolumn{1}{|c|}{$\begin{array}{l}\text { The } \\
\text { accuracy of } \\
\text { the } \\
\text { differences }\end{array}$} \\
\hline $\begin{array}{l}\text { Interpersonal Emotional } \\
\text { Intelligence }\end{array}$ & 43.35 & 33.36 & $\begin{array}{l}\text { There are } \\
\text { differences }\end{array}$ \\
\hline $\begin{array}{l}\text { Intrapersonal Emotional } \\
\text { Intelligence }\end{array}$ & 42.79 & 39.05 & $\begin{array}{l}\text { No } \\
\text { differences }\end{array}$ \\
\hline Emotions understanding & 43.6 & 33.82 & $\begin{array}{l}\text { There are } \\
\text { differences }\end{array}$ \\
\hline Emotion management & 43.75 & 39.25 & $\begin{array}{l}\text { No } \\
\text { differences }\end{array}$ \\
\hline $\begin{array}{l}\text { Total Emotional } \\
\text { Intelligence level }\end{array}$ & 86.14 & 72.41 & $\begin{array}{l}\text { There are } \\
\text { differences }\end{array}$ \\
\hline
\end{tabular}

Teenagers enrolled in foreign language courses focus on communication and work with people of different cultures and emotional restraint, the same as emotion recognition difficulties, may discourage these plans. Therefore, methods of teaching foreign language in Vietnam should include acting elements; pay more attention to the definition of emotions. The ability to apply educational technologies aimed not only at learning, but also at the emotional intelligence development, depending on the ethnic and cultural characteristics of children, should be included in the training program for foreign language teachers.

\section{Discussion}

In the study of the social skills and emotional intelligence development of Ukrainian teenagers, O. Vlasova (Vlasova, 2005) concludes, "the main determinants of the effective deployment of this complex and multidimensional process of the human psyche at the age of 11-12 are a significant increase in such students' attitudes to dominance in interpersonal contacts. We tend to consider such growth as a kind of socio-psychological equivalent of the formation of the subjectivity of these individuals as active carriers of the social "Self" of the individual, which defines itself through the reaction to its actions of 
the reference environment of peers. Such a psychological situation primarily provokes the growth of its socio-emotional and socio-conative properties associated with the further active formation of the operational component of the relevant social skills in terms of formation of emotional standards of facial expressions and adaptive strategies for adequate response in conflict, emotionally charged situations of frustration. An important role in the formation of the optimal communicative style of younger tennagers is played not only by mastering socionormative patterns of behavior and evaluation of others, but also the general attitude of people of this age to active communication with peers, responsible attitude. The development of their own causal-attributive and speech properties, which goes hand in hand with the general intellectual development of such persons, puts these skills at the center among the mechanisms of their socio-psychological self-realization, as it allows to have an effective influence on the reference community of classmates, as eloquently evidenced by the associated growth of their social status". In our study, we found less desire of Vietnamese students to dominate, and lower levels of emotional intelligence, which confirms the results obtained by $\mathrm{O}$. Vlasova. This suggests that classes aimed

\section{References}

1. Breus J. Emotional component in the structure of higher education / YU. V. Breus // Humanitarni aspekty formuvannya osobystosti : Zbirnyk statey VI Vseukrayins'koyi naukovoyi konferentsiyi, 27 kvitnya 2012 r. - L'viv : LDU BZHD, 2012. - S. 277-287 at developing active communication in English classes and the creation of a reference community in informal education will contribute to the formation of students' social skills.

\section{Conclusions}

Emotional intelligence in the teenagers affect their position in the group, professional inclinations, to some extent the locus of control and psychological defenses. There is a difference between Ukrainian and Vietnamese teenagers on interpersonal emotional intelligence and emotion recognition. Therefore, methods of foreign language teaching in Vietnam should include elements of acting skills, with greater emphasis on the emotions definition. The skill to apply educational technologies aimed not only at learning, but also at the emotional intelligence development, depending on the ethnic and cultural characteristics of children, should be included in the training program for foreign language teachers. For Ukrainian teenagers, whose development of emotional intelligence was associated with professional aptitudes, we consider it appropriate to provide additional vocational guidance classes aimed at strengthening creative skills, which will allow starting training of high-level professionals earlier.

2. Vlasova O. I. Psychology of development of social abilities of the person in ontogenesis [full ontogenesis]: scientific monograph./ O.I. Vlasova. - Ottawa: Accent Graphics Communications, 2019. 377 s.

3. Goulman D. Emotional Leadership: The art of managing people based on emotional intelligence / Deniyel 
Goulman, Richard Boyatsis, Enni Makki. - M. : Al'pina Biznes Buks, 2007. - $301 \mathrm{~s}$.

4. Moskalenko L. M. Trends in the development of non-formal education in Ukraine (according to the results of a sociological survey). VISN. L'VIV. UN-TU VISNYK LVIV. UNIV. Seriya sotsiol. 2018. Vyp.12. S. 212220, Ser. Sociol. 2018. Is.12. P. 212 220

DOI: http://dx.doi.org/10.30970/vso.2018 $.12 .12 /$

5. Law of Ukraine "On Education" (2017). Retrieved from: http://zakon0.rada.gov.ua/laws/sho w/2145-19

6. Recommendation of the EU Council on the recognition of non-formal and informal learning. Режим доступу: http://ipq.org.ua/upload/files/files/0 6_Biblioteka/01_Normativna_baza/ 01_Viznznnya_neformalnogo_navc hannya/01_Mignarodni_dokumenti/ council_recommendations_20_d ec_2012_ukr.pdf (Recommendation of the EU Council on the recognition of non-formal and informal learning)

7. Yablokov S. Integration of formal, non-formal and informal learning in English language teaching // Pedahohichni nauky: teoriya, istoriya, innovatsiyni tekhnolohiyi, 2018, № 1 (75) 106-116; ORCID ID 0000-0002-3018-1231 DOI $10.24139 / 2312-5993 / 2018.01 / 106-$ 123. 